\title{
A NOVA CONFIGURAÇÃO DO PODER GLOBAL
}

\author{
John Agnew ${ }^{*}$
}

\begin{abstract}
Hegemonia e império são termos diferentes, que oferecem interpretações profundamente distintas do poder estadunidense e suas manifestações contemporâneas, e de como dito poder pode ser mudado. Depois de uma breve introdução sobre ambos os termos, o texto procura mostrar como a hegemonia pode ser entendida espacialmente e, dessa forma, como a hegemonia dos Estados Unidos dificilmente será canalizada em um império, destacando o fiasco politicomilitar estadunidense no Iraque, apesar da sua aparente supremacia militar depois da Guerra Fria. Finalmente, considerarei a emergência de uma nova configuração do poder global, em que a hegemonia já não pode ser exclusivamente associada aos Estados Unidos. A questão central que subjaz é a necessidade de fugir da armadilha de pensar o poder em termos exclusivamente territoriais: Estados versus impérios. O poder se desenvolve espacialmente de maneiras muito mais complexas, e necessitamos entendê-lo, se quisermos questioná-lo.

PALAVRAS-CHAVE: hegemonia, império, soberania, espacialidade, poder.
\end{abstract}

\section{INTRODUÇÃO}

Uma boa parte do debate acadêmico e popular sobre o papel dos Estados Unidos no mundo insiste em ver o país simplesmente como outro Estado (apesar de maior e mais poderoso), ou como um império, ampliando o evidente significado territorial desse termo para incluir seu controle e influência não-territorial. Nenhum dos enfoques é satisfatório. Por um lado, o mundo atual é considerávelmente diferente, sobretudo no que se refere - se comparamos com épocas anteriores -à geografia do poder. Freqüentemente denominada como a era da "globalização", para assinalar a proliferação de atores (multinacionais, ONG globais, instituições internacionais, etc.) e processos de desenvolvimento (mercados financeiros globalizados, commodity chains globais, etc) que não podem ser relacionados com um único endereço territorial, esta é uma situação mundial que os Estados Unidos ajudaram a provocar, seja de

* Professor do Departamento de Geografia da University of California, Los Angeles (UCLA), Estados Unidos. Department of Geography, UCLA, Los Angeles -CA- USA 90095-1524.jagnew@geog.ucla.edu forma deliberada seja de maneira involuntária. Se isso é um império, seria o primeiro descentrado na história, o que nos sugere que há algo mais que isso. Por outro lado, esse mundo não foi conduzido predominantemente através da coerção direta ou de um governo territorial, mas sim através da incorporação socioeconômica de rotinas e práticas derivadas de (e compatibilizadas com) outras desenvolvidas anteriormente nos Estados Unidos. A melhor palavra para descrever esses processos é hegemonia.

Hegemonia ou império oferecem interpretações profundamente diferentes do poder estadunidense e suas manifestações contemporâneas, e de como dito poder pode ser mudado. É interessante notar que, em muitos de seus usos, ambos os termos não são diferenciados claramente. Em qualquer dos caminhos seguidos, uma "América toda poderosa" normalmente é vista como a responsável por uma nova distribuição do mundo conforme a sua imagem. Desse ponto de vista, a hegemonia é vista simplesmente como um poder coercitivo relativamente espontâneo, exercido por um hegemom ou sede do império. 
Gostaríamos de sugerir que essa interpretação é problemática tanto histórica como analíticamente. De forma mais específica, ambos os termos possuem uma etimologia diferente, assim como significados diversos em inglês e em outros idiomas. Quando usado analiticamente, os termos podem ajudar a clarificar o que aconteceu nas relações dos Estados Unidos com o resto do mundo, como consequência, por exemplo, da guerra do Iraque em 2003. Usados de forma conjunta, também podem oferecer um ponto de partida para entender as relações históricas entre a hegemonia dos Estados Unidos e a América Latina. Apesar de ser uma região com uma vasta experiência de episódios ligados ao império estadunidense, como a conquista permanente de Porto Rico, a longa ocupação do Canal de Panamá ou as intervenções militares periódicas no México e em outros lugares, a história das relações entre os Estados Unidos e a América Latina experimentou, em grande medida, vários tipos de hegemonia desde o começo do século XIX até os dias de hoje.

É possível que exista um império sem hegemonia. Por exemplo, nem a Espanha do século XVI nem Portugal tinham um grande controle sobre a política mundial depois de 1600, mas tinham "posses" territoriais derivadas de sua posição prévia na conquista européia do mundo. Mas, de forma contrária, é também possível ter hegemonia sem império, como, por exemplo, quando os governos dos Estados Unidos, depois da Segunda Guerra Mundial, exerceram uma forte influência sobre a política mundial, porém com uma relativamente pequena extensão territorial. Os governos estadunidenses, em consonância com sua própria origem republicana e anticolonial, assim como com seu recém-descoberto interesse material no livre comércio, se auto-identificaram com um proeminente movimento anticolonial ao redor do mundo. A diferença entre hegemonia e império pode ajudar, nos dias de hoje, a indicar se a hegemonia dos Estados Unidos, depois do fim da Guerra Fria, requer uma maior necessidade de se buscar o império. Em outras palavras, continuará dependendo a hegemonia dos EUA da criação de um império similar ao governado pelos britânicos no final do século XIX, como oposição a continuar trabalhando multilateralmente via alianças e instituições internacionais, mais ainda quando os problemas econômicos estadunidenses incrementam a possibilidade de uma ordem mundial globalizada, em que os Estados Unidos já não são primordiais?

Depois de uma breve introdução sobre ambos os termos, trataremos de mostrar como a hegemonia pode ser entendida espacialmente e, dessa forma, como a hegemonia dos Estados Unidos dificilmente será convertida em um império, destacando o fiasco politico-militar estadunidense no Iraque, apesar da sua aparente supremacia militar depois da Guerra Fria. Finalmente, considerarei a emergência de uma nova configuração do poder global, na qual a hegemonia já não pode ser exclusivamente associada aos Estados Unidos. A questão central que subjaz é a necessidade de fugir da armadilha de pensar o poder em termos exclusivamente territoriais: Estados versus impérios. O poder se desenvolve espacialmente de maneiras muito mais complexas, e necessitamos entendêlo, se quisermos questioná-lo.

\section{HEGEMONIA VERSUSIMPÉRIO}

Assim como muitas palavras políticas e "técnicas”, em línguas européias, hegemonia e império têm raízes gregas e romanas. O termo hegemonia origina-se de uma palavra grega que significa dominação ou liderança, específicamente em um Estado ou nação, em uma liga ou confederação, porém sem uma clara indicação de sentido, se é o resultado de uma coerção ou de um consenso, ou uma combinação de ambos. Sem dúvida, no entanto, a dominação ou liderança exercida não é necessariamente territorial ou contígua. Pode ser ampla e difusa ou concentrada geográficamente. Normalmente, envolve mais do que uma mera coerção econômica e militar, dependendo de cooperação e de um consentimento ativo. "Regras" em comum, instituições e valores formam o núcleo da hegemonia, apoiado por uma posição de superio- 
ridade econômica, cultural e (ou) militar, ocupada pelo Estado ou grupo social que a exerce. A palavra "hegemonia" é, portanto, também uma suposta solução para o dilema de qualquer determinação econômica ou cultural singular, ao postular uma "forma integral de dominação de classe que existe não somente nas instituições políticas e econômicas e nas relações, mas inclusive em formas ativas de experiência e conscientização" (Williams, 1983, p.45). ${ }^{1}$

No contexto da política mundial, os dois sentidos de hegemonia podem ser fusionados de forma proveitosa: por um lado, o sentido de hegemonia do Estado, como se encontra em grande parte da literatura das relações internacionais e dos sistemas-mundo, ou do Estado que sustenta a economia mundial. Por outro lado, há o sentido consensual de dominação, atribuído a Antonio Gramsci e à Escola de Frankfurt, cuja direção leva a inscrever outras práticas e idéias oriundas da experiência do Estado ou grupo social dominante. Na sua dependência da sociedade do mercado, a hegemonia estadunidense, entretanto, é uma forma de dominação social que se tornou cada vez mais transnacional, operando além do auspício e do controle formal do Estado. Mesmo assim, o império, todavia, pode ser uma forma geográfica assumida pela hegemonia. Mas não é somente diferente em termos históricos e analíticos; é praticamente incompatível com a trajetória da hegemonia dos Estados Unidos ao longo dos últimos cinqüenta anos.

Já o termo "império" origina-se do romano e do latim, e significa lei suprema, poder absoluto e domínio. Normalmente, trata-se de um governo em que várias pessoas e territórios estão unidos administrativamente sob uma única jurisdição ou aparato administrativo. Um império pode ser um território contíguo (como nos casos da Antiga Roma e dos impérios russos modernos), mas também um império estrangeiro ou marítimo (como foi o caso do império espanhol, do holandês, do francês e do britânico). Vários estados territoriais têm

${ }^{1}$ Para aprofundar neste sentido ver: Simon, Roger (1991) e Mortan, Adan (2007). um "império" como resultado das conquistas de territórios adjacentes (por exemplo, a Inglaterra no País de Gales e a Irlanda ou os Estados Unidos a oeste das colônias originais). Mas, se essas populações são suficientemente homogeneizadas culturalmente, isso se torna um fator pouco significativo. É a unificação de vários "povos" sob um mesmo domínio o que constitui um traço distintivo do império. Ou seja:

Império é o controle exercido por uma nação sobre outras tanto na regulação de seu comportamento externo como na garantia de formas mínimamente aceitáveis de comportamento interno entre os estados subordinados. Normalmente os estados poderosos fazem o anterior, mas não o último (Rosen, 2003, p. 51).

Freqüentemente, o termo também é usado metaforicamente, ${ }^{2}$ para indicar dominação ou hegemonia, mas esse é um ponto de partida de uma abordagem mais histórica, que perde a capacidade analítica proveniente de ter um leque mais amplo de diferentes palavras para diferentes constelações político-geográficas de poder. ${ }^{3}$

Etimologicamente, a discussão nos leva a alguns limites. Ainda que permita clarificar o que os termos realmente significam no uso comum, pode não coincidir exatamente com o modo como eles são usados atualmente nos círculos acadêmicos e políticos. É melhor, nesse sentido, recorrer às formas como os termos "hegemonia" e "império" têm sido utilizados nas explicações contemporâneas sobre política mundial. ${ }^{4}$ As definições habituais parecem diferenciar duas dimensões do poder: tipo de poder (duro ou brando) e organização geográfica do poder (forte ou débil). Obviamente, trata-se de categorias que estabelecem um tipo ideal. Assim, qualquer exemplo do "mundo real" será uma combinação dessas tendências, e não um mero posicionamento em um extremo ou outro. Se o "poder duro" é sustentado pela coerção militar e o "poder brando" por valores culturais, hábi-

${ }^{2}$ É o caso de Bacevich (2002) e Smith (2003).

${ }^{3}$ Para uma discussão análoga, porém de um alcance mais amplo sobre os graus de hierarquia e territorialidade em relações de segurança, ver Lake (1999, p.17-34).

${ }^{4}$ Ver, por exemplo: Ferguson (2003); Agnew; Corbridge, 1995; Hardt; Negri (2000) e Nye (1990). 
tos e preferências, a organização geográfica do poder varia entre uma organização territorialmente forte até uma extremamente difusa.

As categorias definidas por essas dimensões estão sobredeterminadas, já que não levam em consideração como, em um contexto real, uma influencia a outra. Em outras palavras: elas não estão sempre em oposição total ante a outra, mas sim aparecem em justaposição. As categorias são também predominantemente normativas, já que quem as usa pode vê-las como preferidas ou numa linha progressiva de simpatia; objetivos ou situações que solucionam problemas políticos ou que são, pelo menos, melhores que alternativas. Desse modo, ainda há certa nostalgia de uma imagem benigna do império britânico em certos círculos da Inglaterra e dos Estados Unidos; imagens como o autosacríficio, o chá da tarde, o cricket, o rugby e a ordem política normalmente vêm à tona quando se pensa no império britânico. A lista dos bestseller britânicos nos últimos anos conta com vários livros que contam histórias sobre aqueles que se sacrificaram a si mesmos pelo império. A postura mais apologética parece ser aquela que diz que o império não é necessariamente uma coisa má. De forma ainda mais estridente, marca o retorno da idéia romana do homo sacer: "nós, britânicos, americanos, etc., somos reponsáveis pela manutenção da ordem; eles precisam do nosso savoir faire e nós vamos impô-lo". Ainda mais agora, em tempos de guerra, quando o "terrorismo" é global, sem limites espaciais ou objetivos territoriais específicos, e envolve o colapso da distinção entre o mar, o ar e a terra (Galli, 2003). Há um desajuste aqui entre a responsabilidade do pensamento "inside/outside", por um lado, e a realidade de um mundo contemporâneo que já não é mais divisível entre nítidos e organizados blocos territoriais (2001).

Na mesma linha, a hegemonia recebe alguns significados similares aos do termo império, como uma visão positiva ou negativa, que envolve também uma imagem de uma "liderança" relativamente benigna (e inclusive sacrificada), ou profundas relações de exploração baseadas em consideráveis quotas de poder entre o hegemom e seus subordinados na hierarquia de poder. Entretanto, a diferença real do termo hegemonia, frente ao império, reside em: sua ausência de compromisso explícito, no que se refere à organização per se do poder territorial ou bloco geográfico; sua dependência, em diferentes níveis, em persuadir ou gratificar os subordinados ao invés de premiar ou utilizar imediatamente a coerção, apesar de que um império "absolutamente hegemônico" nunca seja alcançado exclusivamente através de medidas coercitivas. Se pudermos dar, pelo menos, alguma credibilidade a evidências de provas experimentais realizadas em laboratórios psicológicos, isso sugere que "Quase Hegemons" são

inclusive menos atenciosos aos interesses do sócio minoritário que um ditador absoluto, que não necessita aliados. [...] Quando temos poder absoluto sobre outros, nós levamos em conta alguns dos seus interesses, como uma questão de princípio moral (Goodin, 2003, p. 123-124).

Mas, quando outros também detém poder, "a sensação de ter de negociar com os demais praticamente concede ao ‘Quase Hegemom' permissão para ignorar os interesses dos outros” (p.125).

A União Européia (UE) oferece um bom exemplo contemporâneo de uma forma de hegemonia sem império, dentro de um mundo regionalizado (Leonard, 2003, p.132). Os neoconservadores estadunidenses, que planejaram a guerra do Iraque em 2003, lógicamente desestimam a UE, assim como Stalin rejeitava o Papa: "Quantos batalhões você têm?" Contudo, isso é perder totalmente o eixo central. A UE possui um vasto alcance moral e legal. A partir do momento em que foi se expandindo a mais países e cobrindo mais aspectos de regulação política, a UE foi se inserindo dentro da vida quotidiana não somente dos países-membro, mas também daqueles que gostariam de fazer parte e (ou) aqueles que a comerciam com o bloco.

Em primeiro lugar, expande-se sigilosamente. Sua influência se difunde, em grande parte, através das instituições existentes, que criam e impõem padrões comuns. Em segundo lugar, a 
União Européia assegura seu marco legal através de assinaturas e acordos implicitamente ameaçadores, enquanto, no marco externo às suas fronteiras, ameaça os países e as empresas com o isolamento. Empresários dos Estados Unidos, por exemplo, devem seguir as regulações impostas pela UE para ter acesso ao mercado comunitário. Como terceiro ponto, a UE funciona como uma rede e não como um sistema de controle e comando. Henry Kissinger, certa vez, queixou-se que a Europa não tinha um simples número de telefone para o qual ele pudesse ligar quando enfrentasse uma crise na política exterior. Esse telefone continua sem existir. Trata-se, melhor dito, de uma rede de centros unidos em torno a objetivos e políticas comuns. Como resultado, pode se expandir sem colapsar, tanto nos âmbitos em que atua como na área geográfica que atinge. E, mesmo que uma das desvantagens seja poder alcançar consensos rápidos em situações de crise, isso permite uma relativa influência da administração, que promove reformas econômicas e políticas através dos canais existentes, não centralizando o poder em um único centro.

\section{COMOAHEGEMONIAOPERAESPACIALMENTE}

A espacialidade da hegemonia não é simplesmente aquela projetada pela territorialidade estatal, por um poder singular, ou aquela experimentada por uma unidade subordinada. Um grande esforço recente dentro da geografia política tem sido destinado a superar a oposição problemática entre, por um lado, um território estatal isolado, com completa soberania, e, por outro lado, o imperialismo da subordinação territorial dentro de um império. Podem-se identificar pelo menos quatro modelos de espacialidade do poder através dos quais a hegemonia opera. ${ }^{5}$ Cada um desses modelos está intrínsecamente associado a uma série de

${ }^{5} \mathrm{Me}$ inspiro aqui nos trabalhos de Marie-Françoise Durand, Jacques Lévy e Denis Retaillé (1992) e Lévy (1997), que usaram modelos ideais de padróes e interações culturais e econômicas para interpretar mudanças de longa duração na política mundial. condições político-econômicas e tecnológicas, assim como a interpretações culturais. A lógica fundamental dessa abordagem é a de que a espacialidade dominante do poder mudará quando as condições materiais e os modos associados de interpretação delas mudem. Ditos processos de mudança não são inferidos como completamente espontâneos. Pelo contrário, é uma aproximação que parte da historicidade da espacialidade e que implica tanto forças materiais e perspectivas intelectuais como interações de representação em meio a uma série de práticas ou hegemonias, para produzir a espacialidade do poder predominante dentro de um determinado período histórico (Agnew; Corbridge, 1995, p. 5-23).

Mas cada modelo espacial também possui uma validez sincrônica, já que o poder político, em qualquer época, nunca pode ser totalmente reduzido a somente um deles. De maneira próxima à discussão travada por Karl Polanyi (1944) sobre a sociedade de mercado, em termos de emergência de um intercâmbio de mercado que supere a reciprocidade e a redistribuição como princípios da integração econômica, quando um dos modelos predomina sobre outros, estes não são tão eclipsados como lugar ou ocupam um papel subordinado. Os modelos oferecem, desse modo, não somente uma forma de buscar a historicidade do poder político, senão também uma forma de insistir na complexidade da espacialidade do poder em qualquer período histórico.

No primeiro modelo, o de conjuntos mundiais ("ensemble of worlds"), grupos humanos vivem em civilizações ou áreas culturais separadas, com uma comunicação e uma interação limitada entre eles. Dentro desse modelo, cada área têm um profundo sentimento de diferença para além das suas fronteiras, sem dispor de qualquer concepção das características particulares dos "outros". O poder político é, de maneira geral, orientado internamente e dirigido para a manutenção dinástica da ordem interna. Sua espacialidade está baseada em uma forte concepção física do espaço como uma distância a ser reduzida, ou uma circulação que deve ser controlada. 
Por outro lado, nos encontramos com o segundo modelo: o modelo geopolítico dos estados em um campo de forças (field of forces), que se caracteriza por unidades territoriais rigidamente demarcadas, onde cada estado pode ganhar mais poder à custa dos outros, tendo um controle total sobre seu próprio território. É semelhante a um campo de forças na física mecânica, onde os estados exercem força em certa direção, e o resultado da resposta mecânica depende da população e (ou) dos recursos de que cada um pode dispor para suportar, assim como da força e do uso potencial do valor supremo da força para além das fronteiras estatais. Desse modo, a espacialidade dominante é a do Estado territorial, cujas fronteiras políticas são responsáveis por delimitar a maioria das atividades sociais, econômicas e políticas. As elites políticas são, nesse caso, as elites do Estado, havendo uma grande semelhança e uma retroalimentação entre suas práticas e discursos.

O terceiro modelo de espacialidade do poder através do qual a hegemonia opera é o de rede hierárquica (hierarchical network). Esse é o modelo de estrutura espacial da economia-mundo, em que centro, periferia e semiperiferias se conectam por fluxos de mercadorias, pessoas e investimentos. As transações estão baseadas fundamentalmente em um intercâmbio de mercado que produz um desenvolvimento desigual, com fluxos desencadeados por redes de comércio e comunicação que levam a concentrações regionais de relativa riqueza ou probreza. A espacialidade em questão é a das redes espaciais que utilizam conjuntamente uma hierarquia de "nós" e áreas, onde se concentram os fluxos de pessoas, mercadorias, capital e informação. Na atualidade, essas redes são particularmente importantes na ligação de cidades e regiões onde estão constituídos os nós sobre os quais gira uma economia global crescentemente conectada. Em algumas circunstâncias, as redes podem desenvolver uma forma reticular onde não há uma estrutura hierárquica ou um centro bem delineado. Esse é o caso, por exemplo, de certas redes em alguns modelos de negócio, em alianças estratégicas, em que a parceria em um espaço, mais que levar a um predomínio de um nó sobre outro, pode acarretar a prevalência notável de alguma rede criminal ou terrorista.

O quarto e último modelo é o da sociedade mundial integrada (integrated world society). Corresponde ao ideal humanista de um mundo onde a integração econômica, as identidades políticas e as comunidades culturais estejam todas estruturadas em uma escala global: uma verdadeira hegemonia coletiva. Mas tal modelo também reflete o aumento da percepção de problemas comuns globais (como as ameaças meio-ambientais ou a mudança climática) que ultrapassam as froteiras estatais, a inutilidade de conflitos armados entre os estados com a presença de armas nucleares e as vantagens de defesa ante as ofensivas dos atuais tempos de guerra, assim como o crescimento de uma "opinião pública" internacional.

No mundo contemporâneo, há evidências da coexistência de cada um desses modelos, com os antigos modelos territoriais ligeiramente em eclipse e com um ressurgimento do modelo de redes depois de um período de cem anos de predomínio do modelo de campo de forças - ainda que não fosse o único (Storper, 1997; Dicken et al, 2001). Se, por um lado, a tendência de separatismo regional existente no seio dos estados leva a uma fragmentação que pode reforçar o modelo de campo de forças, com a emergência de novos estados, por outro lado, a globalização econômica e a unificação cultural global caminha no sentido de reforçar a rede hierarquizada e o modelo de sociedade mundial integrada. Ao mesmo tempo, movimentos para a unificação político-econômica (como no caso da União Européia) e o desenvolvimento de movimentos culturais com um forte elemento territorial (como no caso dos movimentos de integração islâmicos) tendem a criar pressões para a reafirmação de um modelo de "conjuntos mundiais".

Historicamente, no entanto, tem havido um movimento de um modelo para outro, como um elemento hegemônico ou direcionado. Nesse sentido, gostaria de propor um esquema teórico elaborado a partir do trabalho de Durand et al (1992), no qual, primeiramente, o modelo de "conjuntos 
mundiais" deu lugar lentamente ao modelo de "campo de forças" em torno a $1500 \mathrm{dC}$, a partir do momento em que emergiu o sistema europeu. As hegemonias tendiam a variar geográficamente, de modo que, no século XIX, uma balança de poder da hegemonia era dominante na Europa. Entretanto, as hegemonias imperiais foram superiores em grande parte do resto do mundo, nos Estados Unidos, na América Latina, nos vários impérios europeus na África, etc., com a exceção do caso da hegemonia de bens públicos exercida pela GrãBretanha, através do seu papel de defensora da bandeira do ouro, em um sistema de comércio multilateral que unificava uma emergente economia mundial.

Assim como esse modelo foi estabelecendo a sua posição dominante, a moderna "rede hierarquizada" começou também a dar seus primeiros passos no interior e ao redor do marco previsto pelo sistema estatal. Sob a influência do colonialismo europeu, a parte do mundo em que os estados se reconhecem como atores legítimos (que é hoje muitas vezes chamada de "Norte Global", além dos estados da América Latina) se divorciou daquelas regióes onde esse estatuto foi negado (Doty, 1996). Com a independência de países da África e Ásia, após a Segunda Guerra Mundial, inúmeros novos Estados, independentemente da sua relativa eficácia política, passaram a ocupar a maior parte da superfície terrestre do mundo. Porém muitos desses novos estados eram "clientes" dos Estados Unidos ou da União Soviética - parte de suas respectivas esferas de influência hegemônica -, ou zonas de violento conflito. No campo de forças, dificilmente podem ser considerados com forças iguais.

Desde 1945, o modelo de rede hierárquica se tornou cada vez mais central para a distribuição do poder político, como um resultado do aumento da penetração dos territórios estatais no comércio global, da população e dos fluxos de investimento sob a hegemonia dos Estados Unidos. Esse é um momento de hegemonia verdadeiramente planetária - o primeiro na história - tanto no que diz respeito ao âmbito geográfico como ao da potencialidade de sua influência funcional, baseada nos princípios da sociedade de mercado, até mesmo quando seu principal agente, os Estados Unidos, torna-se menos central.

Com o fim da Guerra Fria, que tinha produzido um importante restabelecimento do modelo de campo de forças entre os estados mais poderosos, o modelo de redes hierárquicas se encontra em ascendência, com os primeiros sinais do início de uma tendência para um modelo de "sociedade mundial integrada”. Mas este é ainda somente o começo de sua infância. Esse quadro, naturalmente, apenas aponta a tendências de longo prazo. Aquilo que se pretende é proporcionar uma aproximação da espacialidade histórica do poder político, associada em diferentes épocas com diferentes modelos de espacialidade dominante e a coexistência de outros. Elaborar "tipos-ideais" é uma maneira de pensar o mundo, e não uma forma de substituir os momentos históricos e os lugares, assim como as complexidades atuais.

\section{A HEGEMONIA DOS EUA DEPOIS DA GUER- RA FRIA}

As perspectivas assinaladas sobre hegemonia e império podem ser brevemente examinadas empiricamente, à luz das tendências experimentadas nos Estados Unidos e de suas relações com o resto do mundo desde o final da Guerra Fria, no começo da década de 1990. Identificarei quatro pontos:

1. O primeiro é a evidente superioridade militar dos Estados Unidos, se comparado com outros países ou alianças. Em termos absolutos, os Estados Unidos gastou, no ano 2000, pouco menos de $\$ 300$ milhões de dólares. Já a OTAN européia gastou ao redor de $\$ 152$ milhões, enquanto a Rússia gastou aproximadamente $\$ 50$ milhões de dólares. Já em termos relativos, os Estados Unidos gastou pouco menos de 3\% do seu PIB, enquanto a França gastou quase um 2,5\% do seu PIB. Entre os cinco primeiros países em capacidade de defesa, os EUA é ab- 
solutamente superior, considerados em conjunto, mas gere isso com apenas 0,5\% mais do seu PIB em gastos de defesa do que o segundo colocado. No entanto, dada a vulnerabilidade dos EUA frente às tecnologias atuais, tal como aviões de passageiros transformados em armas, não há nada certo sobre se essa vantagem absoluta da capacidade defensiva é real em caso de uma guerra contra a as redes terroristas, por exemplo.

2. Os Estados Unidos precisam de capitais estrangeiros para financiar tanto suas despesas públicas como seu alto padrão de consumo de massa. Devido ao fato de que a taxa da poupança nacional é muito baixa, as importações cada vez mais superam as exportações, e, à exceção de alguns anos em torno de 2000, o governo federal dos EUA tem tido um grande déficit entre o que se arrecada em receitas e se gasta em defesa, segurança social e outros serviços. Ou seja: os Estados Unidos necessitam atrair investimentos de todo o mundo para o financiamento da economia nacional. Agora, não há nada necessariamente problemático em termos econômicos sobre esse déficit da balança de pagamentos se, ceteris paribus, o mundo é visto como beneficiário do presente estado de coisas por aqueles que controlam os fluxos de capitais. No entanto, isso significa que os Estados Unidos depende cada vez mais da "boa vontade" dos investidores estrangeiros, incluindo os governos estrangeiros, apesar da sua assombrosa capacidade militar.

3. Os Estados Unidos também têm um alto níve de dependência de determinados recursos importados, em especial do petróleo. Praticamente $40 \%$ do petróleo é proveniente do Oriente Médio. Isso significa que a disponibilidade de petróleo na região é uma consideração importante na política exterior dos EUA. Também significa que, dada a vulnerabilidade do abastecimento de petróleo devido à instabilidade política e as ameaças terroristas, o país se tornou cada vez mais dependente do petróleo em uma parte do mundo que historicamente tem apoia- do déspotas e regimes autoritários para manter seu fornecimento. É importante notar, todavia, que alguns outros países, como o Japão e a China, são ainda mais dependentes do petróleo do Oriente Médio do que os Estados Unidos.

4. Por último, sem a União Soviética ou outra ameaça global de proporção semelhante, é cada vez mais difícil, para os governos dos Estados Unidos, "disciplinar" aliados que sigam sua liderança ou aceitem suas decisões unilaterais (todas aquelas tomadas sem consulta, negociação e mediante acordos). Durante a Guerra Fria, a percepção de um perigo comum proveniente da União Soviética manteve os aliados alinhados. Ausente tal ameaça, esses países tenderam a desviar-se da agenda pautada pelos estadunidenses em muitos aspectos. A chamada "guerra contra o terrorismo" está a revelarse sem substitutos. Como resultado, é perceptível uma abertura de grandes fissuras entre os Estados Unidos e seus antigos aliados na Ásia e na Europa.

Em termos gerais, desde o fim da Guerra Fria, os Estados Unidos têm adquirido uma posição global de dominação militar, como pode ser constatado com sua despesa militar. Saber até que ponto isso é sustentável economicamente depende tanto da vontade dos estrangeiros para financiar a economia estadunidense (e o governo federal), como da própria capacidade econômica dos Estados Unidos. Isso, unido à ausência de uma força externa disciplinadora sobre aliados, aconselharia cautela na tomada de decisões unilaterais. Porém, como já assinalamos, outros países, como o Japão, enfrentam níveis similares de dependência. Tanto uma ação conjunta com os aliados para promover a estabilidade no fornecimento de produtos como tentativas de reduzir a demanda por petróleo no país de origem poderiam fazer mais sentido do que as estratégias nacionais dedicadas à ação militar unilateral. 


\section{A GUERRA DO IRAQUE: um momento crucial?}

O momento presente é crucial para a direção de um raciocínio geopolítico dos Estados Unidos ao longo da próxima década. É acertado dizer que a posição geopolítica dos EUA, desde a Segunda Guerra Mundial, tem sido baseada, em grande medida, na hegemonia garantida mediante mecanismos multilaterais e de mercado, embora tal quadro sofresse um enfraquecimento considerável desde a década de $1970 .{ }^{6}$ Mas essa forma de hegemonia teve inúmeras vantagens e relativamente poucos custos para os Estados Unidos. Entre os benefícios estão:

1. A existência do que poderíamos chamar um "império light": um nível relativamente baixo de gastos em defesa, se analisamos a percentagem do PIB (Ignatieff, 2003). Um "Império total", ou uma "Hegemonia absoluta", seria muito mais caro.

2. A habilidade de usar os dólares estadunidenses para exportar problemas domésticos para o resto do mundo, através da manipulação da taxa de câmbio e da oferta monetária

3. A capacidade ideológica para utilizar até o patrimônio republicano dos Estados Unidos para obter vantagem material ao redor do mundo.

Entre os custos envolvidos estão:

1. Os acordos de segurança com os aliados.

2. A aceitação da necessidade de se envolver em diplomacia com resultados nem sempre desejados.

A principal tentação do império é que ele já não precisa consultar os aliados ou tomá-los a sério. O desprezo da administração Bush pela chamada "comunidade internacional" é sintomático disso. ${ }^{7}$ Uma administração direta ou uma nomeação forçada dos regimes substitutos também daria ao governo dos Estados Unidos muito mais liberdade para exercer uma doutrina de guerra preventiva contra estados como o Irã, Síria, a Coréia do

\footnotetext{
${ }^{6}$ Ver o capítulo 7 de Agnew e Corbridge (1995).

${ }^{7}$ Evidente nos pronunciamentos oficiais dos Estados Unidos sobre o papel das Nações Unidas antes do ataque ao Iraque em 2003.
}

Norte, Cuba, e outros, considerados como uma ameaça, de um modo ou de outro, para os EUA.É claro que dita doutrina não é aceita por toda a "comunidade internacional”. Além disso, se o império realmente parece funcionar, os aliados também podem ser excluídos dos frutos da vitória. É provável, no entanto, que os custos adicionais sejam elevados. Entre eles:

1. Uma partilha muito inferior dos custos militares e administrativos (como aconteceu, por exemplo, com a Guerra do Golfo de 1991).

2. Fixação de um precedente para que outros possam tomar ações preventivas (por exemplo, Paquistão contra a Índia ou a China a Taiwan).

3. Minar a base institucional das "regras" de comportamento internacionais que lançaram as bases para a globalização econômica contemporânea, em grande parte auspiciadas pelos próprios Estados Unidos.

4. A contradição de reivindicações para impor práticas democráticas em outros países utilizando a força.

5. Vulnerabilidade dos Estados Unidos a represálias econômicas e militares assimétricas.

6. Limites da crítica e dissenso interno sobre as aventuras imperiais, minando o que resta do modelo republicano.

7. Fracasso em observar que a destruição dos regimes seculares no mundo árabe, como o do Iraque, é um objetivo declarado da Al-Qaeda, por detrás dos atentados terroristas de 11 de setembro de 2001. Ao atacar e conquistar o Iraque, os Estados Unidos estão, de fato, fazendo um franco favor para eles.

\section{PARA ALÉM DA HEGEMONIA DOS EUA: a nova configuração do poder global}

Os custos e benefícios do império precisam ser contextualizados nos dias de hoje. Os Estados e outros atores da política mundial assumem, cada vez mais, acordos globais que apontam contínuamente para além tanto dos EUA hegemom como do EUA Império. A economia mundial, hoje, é verdadei- 
ramente global, em um grau nunca visto antes, no seu âmbito geográfico; o ritmo das transações vincula lugares amplamente dispersos dentro dela e se desenvolve diferentemente de simples formas territoriais de autoridade política em toda uma vasta gama de domínios (econômico, social e político). E isso se tornou assim, em grande medida, devido à própria natureza da hegemonia dos Estados Unidos.

No entanto, essa hegemonia tornou-se cada vez mais redundante. A influência do capital é agora mediada através de mercados financeiros globais, do fluxo de comércio no âmbito das empresas multinacionais e das limitadas capacidades das instituições de regulação global. Os seus benefícios e custos agora caíram em todas as partes do mundo. Se eles continuarem em uma queda desigual, os desníveis já não poderão ser buscados país por país nem bloco por bloco. A variação geográfica do crescimento econômico é cada vez mais local e regional, dentro dos países. Mas não é o global o que é "novo" na globalização, senão uma mudança da lógica geográfica da economia mundial. Ou seja: o novo não é a "globality", mas, sim, a sua combinação de redes globais e a fragmentação territorial localizada. No global "passado", a economia mundial foi, em grande parte, estruturada (mesmo que nunca completamente) em torno de entidades territoriais, como os estados, impérios coloniais e esferas de influência geopolítica. A principal novidade de hoje é o papel crescente na prosperidade econômica e no subdesenvolvimento dos fluxos transfronteiriços em relação aos Estados nacionais e às redes que ligam cidades entre si e com suas zonas interiores, assim como o aumento da diferenciação entre as localidades e regiões, como resultado dos desvios espaciais construídos entre o fluxo das redes. Isso é evidente em toda a América Latina, no âmbito de países onde as disparidades internas de rendimentos e de desenvolvimento econômico são cada vez mais evidentes, na medida em que algumas regióes aproveitam da sua inserção nos circuitos globais de capital, enquanto outras ficam totalmente fora, ou sofrem as nefastas consequências das mais convencionais estratégias de desenvolvimento, tais como a compra dos cultivos ou o esgotamento das fontes minerais.

Longe do "fim" da geografia, a globalização implica sua reformulação, deixando de lado o mapeamento econômico do mundo em termos de estados territoriais, para entrar em um mosaico mais complexo de estados, regiões, cidades "globais" e "regionais" e localidades diferencialmente integradas na economia global. Existe uma geopolítica da globalização contemporânea, tanto no que diz respeito às suas origens - com os EUA como inspiração - como em relação à sua operação contínua - que avança para além das suas origens estadounidenses. Culturalmente, portanto, o mundo é também cada vez mais "criolizado", em vez de simplesmente "americanizado" (Pells, 1997). Isso não é nada surpreendente, dada a crescente heterogeneidade cultural dos próprios Estados Unidos e a necessidade de as empresas - quer sejam americanas, européias, ou de qualquer parte do globo - adaptarem os seus produtos para diferentes públicos ou mercados no país e no exterior. Essencialmente, pela primeira vez desde o século XVIII, o "berço do capitalismo" - Europa Ocidental e os Estados Unidos - "tem tanto medo da rapidez da mudança como da periferia” (Desai, 2002, p.305). Isso quer dizer que não apenas a África ou a América Latina, mas também a América do Norte e a Europa estão agora sujeitos a condições relativamente mais igualitárias ante os caprichos dos mercados mundiais. Mais especificamente, a mudança política recente mais importante é a diminuição dramática da autonomia dos Estados mais poderosos, em face da globalização da produção, do comércio, da tecnologia e da comunicação.

O poder do Estado moderno sempre teve dois aspectos que o respaldaram: o absolutismo e o poder de infra-estrutura (Mann, 1984). Se o primeiro refere-se ao poder exercido pelas elites socioeconômicas que ocupam cargos políticos, esse último remete para o poder revertido para o Estado como tal, a partir da sua entrega de infra-estruturas ou bens públicos à população. Historicamente, o aumento da importância relativa do "poder 
infra-estrutural", quando as elites foram forçadas, através de lutas populares, a se tornarem mais responsáveis pelas respectivas populações, levou a uma territorialização da autoridade política. Até recentemente, as tecnologias de prestação de bens públicos foram construídas com um viés territorial, e não menos relacionadas com a captura de externalidades positivas.

Cada vez mais, no entanto, o "poder infraestrutural" pode ser implantado no seio das redes que, embora instaladas em locais específicos, não são necessariamente territoriais nos domínios externos que produzem. Assim, moedas, sistemas de medidas, a negociação de redes, uma oferta educativa de bem-estar e de serviços não necessitam estar associados com uma adesão exclusiva a um Estado-nação convencional. Novas implementações de um poder de infra-estruturas podem tanto estar desterritorializadas em um Estado, como re-territorializarem a adesão em torno de cidades e zonas interiores, regiões, em âmbito continental e entidades políticas, como a União Européia (Scott, 1998). Existe um simultâneo aumento e uma redução de escala dos domínios geográficos relevantes do poder de infra-estruturas, a depender das políticas econômicas de escala de diferentes bens públicos regulatórios, produtivos e redistributivos. Conseqüentemente,

... quanto mais economias de escala dos bens e valores dominantes divergem da dimensão estrutural do Estado nacional - e quanto mais essas divergências incidam entre si de formas complexas -, então maior a autoridade, a legitimidade, a capacidade de decisão política e de implementação eficaz da política do estado, que será erosionado e prejudicado, tanto por fora como por dentro (Cerny, 1995, p. 621).

No caso dos Estados Unidos, essa situação é agravada pelas dificuldades de coordenação e direção dentro do complexo sistema governamental. ${ }^{8}$

Usando o exemplo do sistema monetário mundial, os EUA têm incentivado o uso de dólares estadunidenses no mundo do comércio e das

${ }^{8}$ Ver o capítulo 5 de Agnew (2005). finanças desde o colapso do sistema de Bretton Woods, no início dos anos 1970. Inicialmente concebido pela administração Nixon para tornar as exportações mais competitivas e para acirrar o déficit da balança de pagamentos, a flutuação do dólar estadunidense sobre outras moedas foi um importante - independentemente de ser voluntário ou não - estímulo à globalização, tanto no sentido de facilitar os intercâmbios comerciais como no incentivo à explosão das finanças globais. ${ }^{9}$ Embora o governo dos Estados Unidos, na medida em que pode influenciar a Reserva Federal (Banco Central dos EUA), ainda possa usar seu dólares para manipular a economia mundial em benefício dos seus produtores e consumidores, existem limites reais para isso, pois os EUA dependem do fluxo maciço de investimentos originados no exterior, sendo que uma grande proporção de dólares em circulação está fora dos limites territoriais dos Estados Unidos. Além disso, outros governos (como o da China) fixam estreitamente suas moedas ao dólar, construindo grandes reservas utilizadas para manter a paridade e, assim, manter os preços das suas exportações competitivas no mercado doméstico dos EUA.

Como conseqüência, os dólares estadunidenses e outras moedas de ampla circulação (como o euro e o iene japonês) vêm erodindo lentamente o poder de infraestrutura monetária independente, tanto nos estados em que circulam suas moedas como neles próprios, já que eles, e não apenas os portadores de divisas menos potentes, estão recebendo também os choques de moedas de "fora". Os mercados globais determinam, cada vez mais, os valores relativos do que ainda se encontra nominalmente como moedas nacionais. De fato, o "dentro" e o "fora" do Estado são cada vez mais questionados quanto a seu significado material. Assim, em uma grande área em que os EUA exerceram previamente uma hegemonia econômica, há sinais crescentes de hegemonia - nos mercados monetá-

${ }^{9}$ Ver Andrews (1994) e Helleiner (1994). Para uma excelente revisão dos prós e contras do papel dos recursos financeiros na mudança da soberania estatal, ver Helleiner (1999). 
rios globais - sem um único Estado hegemom, como os Estados Unidos, que possa interceder eficazmente e encaminhá-la de acordo com seu próprio benefício.

(Tradução de Breno Marqués Bringel)

(Recebido para publicação em junho de 2008)

(Aceito em agosto de 2008)

\section{REFERÊNCIAS}

AGNEW, John. Hegemony: the new shape of global power. Philadelphia: Temple University Press, 2005.

; CORBRIDGE, Stuart. Mastering space: hegemony, territory and international political economy. London Routledge, 1995.

ANDREWS, David M. Capital mobility and state autonomy: towards a structural theory of international monetary relations. International Studies Quarterly, Cambridge, v. 38, n. 2, p.193-218, 1994.

BACEVICH, Andrew. American empire: the realities and consequences of US diplomacy. Cambridge MA: Harvard University Press, 2002.

CERNY, Philip G. Globalization and the changing logic of collective action International Organization, Massachusetts, v. 49, n.4, 1995.

DESAI, Meghnad. Marx's revenge: the resurgence of capitalism and the death of statist socialism. London: Verso, 2002.

DICKEN, Peter et al. Chains and networks, territories and scales: towards a relational framework for analysing the global economy. Global Networks, New York, n.1, p. 89112, 2001. Disponível em: http://courses.nus.edu.sg/ course/geoywc/publication/DKOY_2001.pdf

DOTY, Roxanne Lynn. Imperial encounters: the politic of representation in North-South relations. Minneapolis: University of Minnesota Press, 1996.

DURAND, Marie-Françoise; LÉVY, Jacques Lévy; RETAILLÉ, Denis. Le monde: espaces et systèmes. Paris: Presses de la Fondation Nationale des Sciences Politiques, 1992.

FERGUSON, Niall. Empire: how britain made the modern world. London: BBC Books, 2003.

GALLI, Carlo. Spazi politici. L'éta moderna e l'éta globale. Bologna: Il Mulino, 2001.

. La guerra globale. Rome: Laterza, 2003.

GOODIN, Robert E. How amoral is hegemon? Perspectives on Politics, Massachusetts, n. 1, 2003.

HARDT, Michael; NEGRI, Antonio. Empire. Cambridge, MA: Harvard University Press, 2000.

HELLEINER, Eric. States and the reemergence of global finance: from Bretton Woods to the 1990s. Ithaca, NY: Cornell University Press, 1994.

. Sovereignty, territoriality and the globalization of finance. In: SMITH, David et al (Ed.) States and sovereignty in theg global economy. London: Routledge, 1999.
IGNATIEFF, Michael. Empire Lite. Prospect, New York, p. 36-43, feb., 2003.

LAKE, David A. Entangling relations: american foreign olicy in its 'century. Princeton, NJ: Princeton University Press, 1999.

LEONARD, M. Euro space: combine and conquer. Wired, New York, june, 2003. Disponível em: www.wired.com/ wired/archive/11.06/euro_spc.html

LÉVY, Jacques. Europe: une géographie. Paris: Hachette, 1997.

MANN, Michael. The autonomous power of the state. European Journal of Sociology, Cambridge, n. 25, p. 185213, 1984.

MORTON, Adam D. Unraveling Gramsci: hegemony and passive revolution in the global economy. Londres: Pluto Press, 2007

NYE, Joseph. Bound to lead: the changing nature of American power. New York: Basic Books, 1990.

PELLS, Richard. Not like Us: how europeans have loved, hated, and transformed american culture since world war ii. New York: Basic Books, 1997.

POLANYI, Karl. The great transformation. Boston: Beacon Press, 1944.

ROSEN, Stephen. An empire, if you can keep it. The National Interest, Washington,DC, n.71, Spring 2003.

SCOTT, Allen J. Regions and the world economy. Oxford: Oxford University Press, 1998.

SIMON, Roger. Gramsci's political thought: an introduction. Londres: Lawrence and Wishart, 1991.

SMITH, Neil. American empire: Roosevelt's geographer and the prelude to globalization. Berkeley: University of California Press, 2003.

STORPER, Michael. Territories, flows, and hierarchies in the global economy. In: COX, Robert (Ed.) Spaces of globalization: reasserting the power of the local. New York: Guilford Press, 1997. p. 19-44,

WILLIAMS, Raymond. Keywords: a vocabulary of culture and society. Londres: Harper Collins, 1983. 


\section{THE NEW CONFIGURATION OF GLOBAL POWER}

\author{
John Agnew
}

Hegemony and empire are different words that offer widely distinct interpretations of the power of the United States and their contemporary manifestations, and how this power can be changed. After a brief introduction about both words, we will show how hegemony can be spatially understood and, in this way, how difficult it is for the hegemony of the United States to be channelled in an empire, pointing out the political-military American fiasco in Iraq in spite of her apparent military supremacy after the Cold War. Finally, we will consider the emergency of a new configuration of global power where the hegemony no longer can be exclusively associated to the United States. The underlying central subject is the need to flee the trap of thinking power exclusively in territorial terms: States versus empires. The power grows spatially in much more complex ways and we needed to understand it if we want to question it.

KEYwORDS: hegemony, empire, sovereignty, spatiality, power.

\section{LANOUVELLECONFGURATIONDUPOUVOIRGLOBAL}

\section{John Agnew}

Hégémonie et empire sont des termes différents qui donnent des interprétations extrêmement distinctes du pouvoir nord-américain et de ses manifestations contemporaines et permettent de voir comment ce pouvoir en question peut être modifié. Suite à une brève introduction concernant ces deux termes, nous montrerons comment l'hégémonie peut être perçue dans l'espace et donc, comment l'hégémonie des Etats-Unis difficilement conduira à un empire. Nous mettrons en évidence le fiasco politico militaire des Etats-Unis en Irak malgré une suprématie militaire apparente après la Guerre Froide. Finalement, nous prendrons en considération le surgissement d'une nouvelle configuration du pouvoir global dans lequel l'hégémonie ne peut plus être exclusivement associée aux Etats-Unis. La question principale subjacente consiste à éviter le piège qui est de concevoir le pouvoir en termes exclusivement territoriaux: les Etats versus les empires. Le pouvoir se développe dans l'espace de manière beaucoup plus complexe et il nous faut le comprendre si nous voulons le remettre en question.

Mots-CLÉs: hégémonie, empire, souveraineté, spatialité, pouvoir. 